\title{
Early Morbidity and Perioperative Course of Neonates with Esophageal Atresia and Tracheoesophageal Fistula in a Tertiary Pediatric Surgical Center
}

\author{
Ralf-Bodo Troebs $^{1 *}$, Jan Wald ${ }^{2}$ \\ ${ }^{1}$ Department of Pediatric Surgery, St. Mary's Hospital Herne, St. Elisabeth Group, Ruhr-University of Bochum, Herne, Germany \\ ${ }^{2}$ Department of Diagnostic and Interventional Radiology, St. Mary's Hospital Herne, St. Elisabeth Group, Ruhr-University of Bochum, \\ Herne, Germany \\ Email: *ralf-bodo.troebs@elisabethgruppe.de
}

How to cite this paper: Troebs, R.-B. and Wald, J. (2016) Early Morbidity and Perioperative Course of Neonates with Esophageal Atresia and Tracheoesophageal Fistula in a Tertiary Pediatric Surgical Center. Open Journal of Pediatrics, 6, 191-202. http://dx.doi.org/10.4236/ojped.2016.63028

Received: June 12, 2016

Accepted: August 6, 2016

Published: August 9, 2016

Copyright $\odot 2016$ by authors and Scientific Research Publishing Inc. This work is licensed under the Creative Commons Attribution International License (CC BY 4.0).

http://creativecommons.org/licenses/by/4.0/ (c) (i) Open Access

\section{Abstract}

Background: The management of infants (infs.) with esophageal atresia and tracheoesophageal fistula $(E A \pm T E F)$ is demanding and complex. The aim of this study was to evaluate early morbidity, the timing of surgery, and the results of surgery. Patients and Method: We collected data of 30 consecutive infs. treated for EA \pm TEF between 2006 and 2014. Results: The median gestational age was 38 weeks (12 preterm), and the median Birth Weight (BW) was $2660 \mathrm{~g}$ ( 4 infs. had a BW $<1500 \mathrm{~g}$ ). The median Apgar score at 10 minutes was 10 (range 7 - 10). The median umbilical artery $\mathrm{pH}(\mathrm{UapH})$ was 7.30. According to the Spitz classification, 19 infs. were group 1, 9 infs. were group 2 , and 2 infs. were group 3. Surgical repair was performed in 29 cases (25 EA; 4 isolated TEF). Once the infs. arrived at the pediatric surgery department, surgery was postponed overnight in 11 cases. The duration of postoperative (p.o.) mechanical ventilation was significantly shorter for operations performed on day 2 after delivery. Twenty-four infs. (83\%) underwent surgery within 2 days after delivery, and 5 infs. had later surgery. Chest drains (p.o.) for pneumothorax were inserted in 6 infs. (21\%), and gastrostomy was performed in 6 cases $(21 \%)$. No re-thoracotomy was required. The median length of hospital stay was 17.5 days (6 to 120). The incidence of p.o. mortality was 1 in 29 (3\%). Discussion: The majority of the infs. presented growth retardation (indicated by low birth weight) and a stable immediate postnatal course. The data from this study support the concept of early but not emergent surgery for the majority of infs. with EA \pm TEF. However, a remarkable rate of perioperative morbidity must be taken into account. Conclusion: Surgery for EA \pm TEF can be performed safely during the first postnatal days with exception of very unstable preterm infants. 


\section{Keywords}

Esophageal Atresia, Tracheoesophageal Fistula, Short-Term Outcome, Morbidity, Urgency, Ventilation, Lengths of Stay

\section{Introduction}

The overall prevalence of Esophageal Atresia (EA) and Tracheoesophageal Fistula (TEF) in Europe was 2.43 cases per 10,000 births [1]. Early recognition and timely surgical repair are the main steps for successful management. The main goals of treatment are to reduce morbidity and to achieve the best possible quality of life for the children and their parents [2]. Surgery involves the dissection of the TEF and anastomosis of the esophagus. Complications and adverse events (immediate, intermediate, and long term) may occur at any time [3].

This is a report that focuses on the perinatal course, perioperative management, and short-term outcome of infants (infs.) with EA and/or TEF. Furthermore, the influence of the timing of surgery on postoperative ventilation was analyzed. The data from this study were interpreted against the background of an international survey on the management of esophageal atresia [4], 3 recently published multi-institutional studies, and data from the European Database of Congenital Anomalies [1] [5]-[7].

\section{Materials and Methods}

In this study, we evaluated all infs. with EA or TEF treated between January 2006 and June 2014 in our department. A total of 30 newborns with EA \pm TEF were identified. All of the infants were born in a perinatal center that did not have a pediatric surgical unit and were transferred to our hospital by local specialized neonatal transporting teams.

We evaluated the clinical records and surgical reports to extract data about the patients' perinatal course, surgery, malformations and in-hospital morbidity.

\subsection{Statistics}

For the statistical analysis, we applied linear regression analysis $(y=A x+B)$ and Pearson's correlation coefficient $(r)$. The non-parametric Mann-Whitney U test was used to compare samples from two unrelated groups. The significance level was tested for $(n-$ 2) degrees of freedom [8].

\subsection{Ethics Statement}

This study was approved by the ethics committee of the Ruhr University of Bochum.

\section{Results}

\subsection{Perinatal Course (Table 1)}

Fifteen (50\%) neonates were delivered by Caesarean Section (CS), 14 were born spon- 
taneously and 1 had an unknown mode of delivery. The infs. had a median gestational age of $38(36 \pm 4)$ weeks (range $29-41)$ and a median BW of $2660(2418 \pm 405) \mathrm{g}$ (range 980 - 3600). Thirteen newborns (43\%) had a BW below $2500 \mathrm{~g}$, and 4 infs. (13\%) had a BW below $1500 \mathrm{~g}$ (3 VLBW, 1 ELBW). In addition, 12 infs. (40\%) were delivered preterm, and 18 were delivered at term $(60 \%)$. The median umbilical artery $\mathrm{pH}(\mathrm{UApH})$ was 7.30 ( $7.29 \pm 0.01$; range 7.13 - 7.38), and the median Apgar scores were 7 (range 5 9) after 1 minute, 9 (range 7 - 10) after 5 minutes, and 10 (range 7 - 10;2 2 Apgar 7; $4 \times$ Apgar 8; 1 successful reanimation) after 10 minutes. In 4 infs., UApH was below 7.20 (range $7.13-7.19$ ).

A prenatal ultrasound diagnosis of EA (polyhydramnios \pm absence of the stomach) had been established in 9 cases (5\%) of 20 infs. with a documented prenatal course.

\subsection{Accompanying Malformations}

In 3 patients (10\%), chromosomal anomalies were detected (1 had Down syndrome; 2 had Edwards syndrome). In 12 infs. (40\%), no accompanying malformations were detected; however, the majority $(\mathrm{n}=18,60 \%)$ of the infs. had severe or remarkable malformations: 6 had MCMs ( 2 had tetralogy of Fallot, 1 had coarctation of the aorta, and 3 had combined atrioventricular septum defects), 7 had skeletal malformations, 3 had central nervous system malformations, 4 had gastrointestinal malformations ( 2 had an annular pancreas, 1 had a dystopic pancreas at the stomach, and 1 had a cloacal malformation), 2 had tracheobronchial malformations (1 had tracheal stenosis and an irregular branching pattern of the right bronchus, and 1 had a tracheal origin of the right upper lobe bronchus), and 1 had diaphragmatic relaxation on the right side. A rightdescending aorta was found in 2 infs. No patient required surgical PDA closure.

\subsection{Timing of Operation, Length of Stay (Table 1)}

The median age at referral to the pediatric surgery unit was 1 day ( $3 \pm 0.7$; range 0 - 54), and $24(83 \%)$ of our patients underwent primary repair within 2 days after delivery. The median age at surgery was 1 day $(4 \pm 0.7$; range 0 - 55).

Table 1. Baseline characteristics.

\begin{tabular}{ccc}
\hline Parameter & Median $($ mean \pm SD) & Minimum/maximum \\
\hline Birth weight $(\mathrm{g})$ & $2660(2418 \pm 405)$ & $983 / 3600$ \\
Gender & 12 females, 18 males & $\#$ \\
Gestational age (wk) & $38(36 \pm 4)$ & $29 / 40$ \\
Apgar score at 10 minutes & $10(9 \pm 1)$ & $7 / 10(1$ reanimation) \\
Umbilical artery pH & $7.30(7.29 \pm 0.01)$ & $7.13 / 7.38$ \\
Preoperative stay in pediatric surgery & $0(0.6 \pm 2)$ & $0 / 2$ \\
Age at repair (n = 29) (days) & $1(4 \pm 1)$ & $0 / 55$ \\
Length of stay (days) & $17.5(27 \pm 9.2)$ & $6-120$ \\
\hline
\end{tabular}

${ }^{*} 3$ patients were transferred under continuous ventilation (over 168, 576, and 984 hours) to a collaborating NICU;

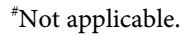


The majority of the patients underwent surgery on the day of admission to the pediatric surgery unit $(n=17)$. However, in 11 cases, surgery was performed on the second day of the pediatric surgery unit stay, and in 2 cases, surgery occurred on the third day (both of these infs. had isolated TEF). In one patient, deterioration related to gastric overextension occurred on the first day of life, and surgery was performed immediately. Thus, the median preoperative stay in the pediatric surgery unit was 0 days $(0.6 \pm 2$; range 0 - 3). For the infant with TEF and trisomy 18, surgery was performed at day 55.

The infs. remained in the pediatric surgery NICU (newborn intensive care unit) for 17.5 days ( $27 \pm 9.2$; range $6-120)$.

\subsection{Type of EA and Surgery}

Twenty-two infs. had EA with distal TEF (Gross type C), 4 infs. had isolated TEF (Gross type E), 2 infs. had EA with proximal and distal fistula (Gross type D), and 2 infs. had isolated EA (Gross type A).

Twenty-nine of the 30 infs. underwent surgery for EA \pm TEF. The flap technique described by Gogh and Bar-Maor [9] [10] was applied in 6 infs. (20\%) to overbridge a wide-gap EA. One infant (BW $1100 \mathrm{~g}$ ) with trisomy 18 and an initially gasless abdomen (Gross type A) presented with perforated necrotizing enterocolitis. For palliative treatment, gastrostomy and enterostomy were performed. This case was excluded from further analysis regarding repair and outcome.

In 23 of 25 patients (92\%) with EA, a single-stage repair was performed; 2 two-stage repairs were performed in one ELBW infant with EA Gross type $C$ and for one infant with type II atresia. This surgery entailed a muscle-sparing right thoracotomy and retropleural dissection. In addition, 1 patient underwent thoracoscopic repair of the EA. All of the infs. received a transanastomotic size 4 to 6 French feeding tube. A routine contrast study was performed at 5 to 7 postoperative days (Figure 1).

In $9(31 \%)$ patients, intrapleural chest drains were inserted during surgery. One infant developed a tension pneumothorax preoperatively, which required drainage. Postoperative pneumothorax occurred in 7 infs. and was drained between the first and the $15^{\text {th }}$ postoperative day in 6 infs. (20\%) (Figure 2).

In addition, we performed 6 gastrostomies $(20 \% ; 3$ during the primary operation, and 3 later to address severe tracheomalacia and impaired swallowing $[n=1]$ and the insertion of a Rehbein thread for bougienage, $n=2$ ).

\subsection{Postoperative Course, Duration of Ventilation (DOV)}

The esophageal anastomosis healed without complications in 24 of 25 infs. with EA. Only the infant who had a primary TEF closure experienced anastomotic leakage after the second-stage anastomosis with tension. This incident was managed conservatively using pleural drainage and antibiotic therapy. Aside from the two infs. who underwent staged repairs, no rethoracotomies were required. Duodenal stenosis caused by annular pancreas was symptomatic after primary repair in 2 cases and was corrected using duodenoduodenostomy. 


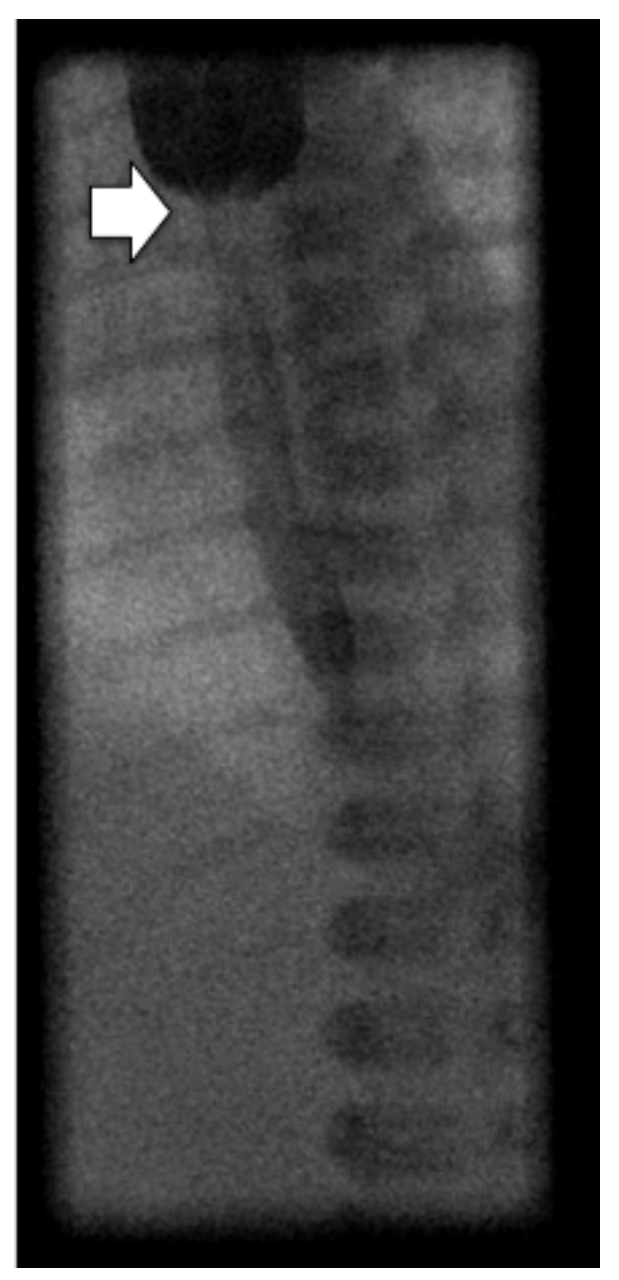

Figure 1. Postoperative contrast study. There is a good evacuation of the hypertrophied upper pouch through the anastomosis (arrow).

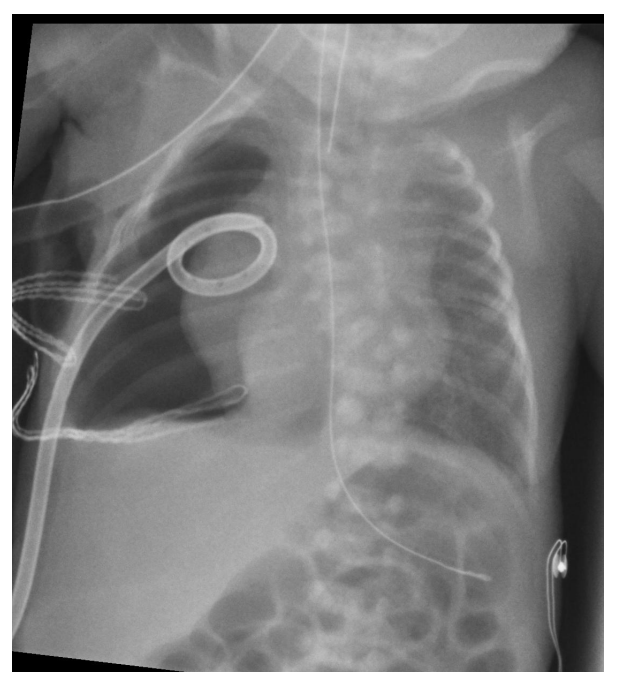

Figure 2. Postoperative tension pneumothorax on the right side. Drainage with an eight French pig tail thoracostomy tube was successful. Severe scoliosis and multiple vertebral malformations are associated. 
After surgery, the total of patients in this study were mechanically ventilated for 134 (194 \pm 200 ) hours (range $46-984)$. After EA \pm TEF repair, the DOV was 173 (213 \pm 209) hours (range 46 - 984), whereas the 4 infs. with isolated TEF had a shorter median postoperative ventilation of $49(73 \pm 64)$ hours (range 25 - 168; $\mathrm{p}=0.057)$.

After exclusion of infs. with isolated TEF, regression analysis revealed a negative regression coefficient between BW and GA and the DOV (BW-DOV: $\mathrm{A}=-0.6, \mathrm{r}=0.2$; GA-DOV: $A=-20.25, r=0.33$; both not significant).

The duration of postoperative ventilation in patients with EA was compared among infs. who underwent surgery on day 0,1 or 2, excluding the patients with isolated TEF (Figure 3). Regarding ventilation time, there were statistically significant differences between patients who had surgery on the day of birth or the first or day of life and infs. operated on at the second day of life.

\subsection{Mortality (Table 2)}

The postoperative in-hospital mortality rate was 1 out of $29(3 \%)$. This mortality rate excludes the infant with trisomy 18 who received only palliative treatment; one infant with EA type $\mathrm{C}$ expired at the age of 5 weeks ( 3 weeks after repair of the diaphragmatic relaxation) as a result of severe pulmonary hypertension and bleeding. An autopsy revealed an intact esophageal anastomosis without recurrent TEF.

\subsection{Limitations}

This study was limited by the small sample of patients treated at a single institution. One strength of this investigation is that the first author had an involved and responsible

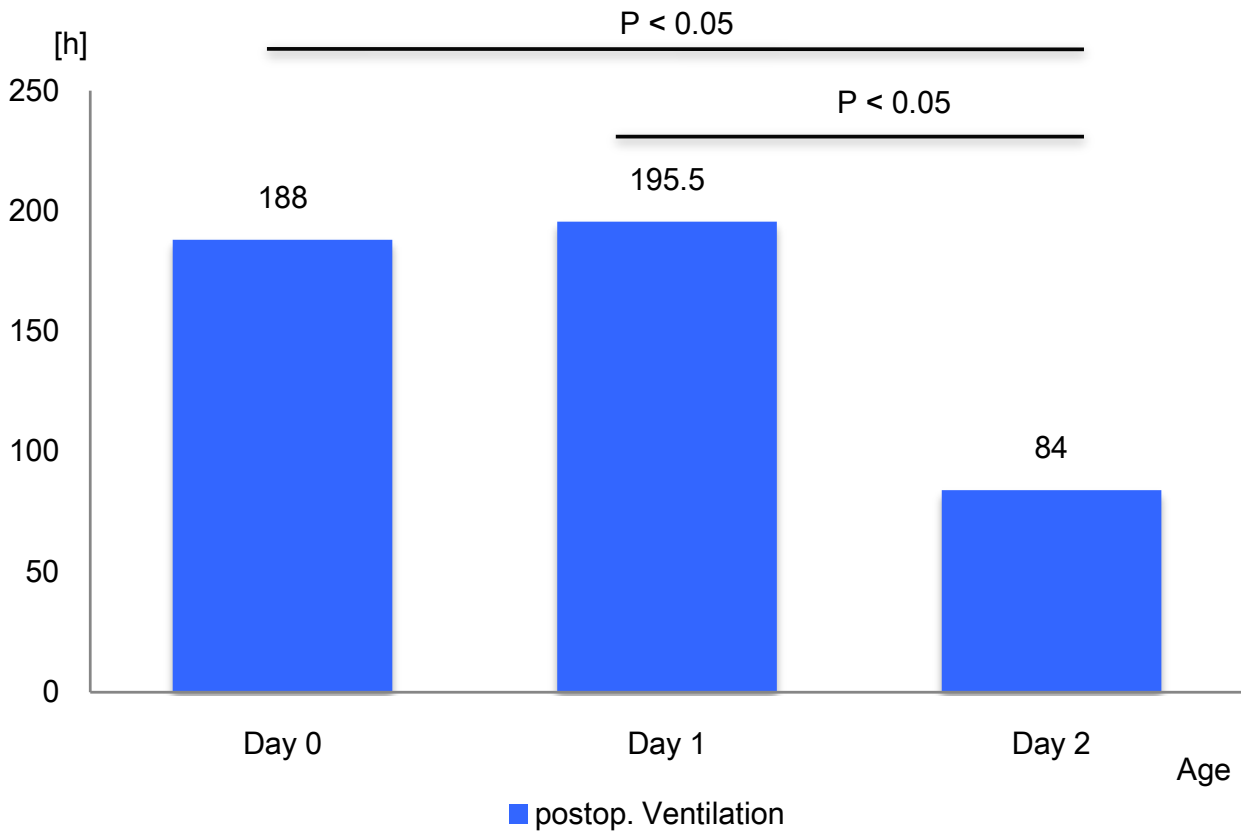

Figure 3. Length of postoperative ventilation (hours) was shorter in newborns operated on day 2 after delivery $(\mathrm{p}<0.05)$. 
Table 2. Risk stratification according to the Spitz classification (2006).

\begin{tabular}{cccc}
\hline Risk & Number & Mortality & Definition \\
\hline Group 1 & $19(63 \%)$ & 0 & BW $>1500$ g, no MCM \\
Group 2 & $9(30 \%)$ & $2(1$ palliative surgery only, 1 pulmonary hypertension $)$ & BW $<1500$ g or MCM \\
Group 3 & $2(7 \%)$ & 0 & BW $<1500$ g and MCM \\
Total & 30 & $2(7 \%)$ & \\
\hline
\end{tabular}

role in the surgery and treatment of all reported cases. Furthermore, complete data sets were available for the vast majority of the investigated parameters. Sample sizes other than the whole group of patients are provided in brackets.

\section{Discussion}

The BW of infs. with EA \pm TEF is an important prognostic factor [6] [7]. According to Spitz's risk classification, a $\mathrm{BW}<1500 \mathrm{~g}$ has a major prognostic impact for survival. Thirteen percent of our patients were VLBW or ELBW infs. In our series, the survival rate for this subgroup of infs. was $100 \%$. However, in larger cohorts, the mortality of patients with BW $<1500 \mathrm{~g}$ is approximately one-fifth or perhaps higher [6] [11] [12]. Half of our patients were delivered via CS, and $40 \%$ of our patients were delivered before 37 weeks of age. This rate of preterm infs. is consistent with the EUROCAT data and the North American results [1] [7].

\subsection{Perinatal Course}

In nearly half of the 20 patients with a documented prenatal course was identified on prenatal ultrasound. The prenatal detection rates for polyhydramnios \pm absent stomach in Europe vary between $<10 \%$ and $>50 \%$ [1], and in a recent Japanese study, 30\% of infs. were identified prenatally [6]. In the presented series, 5 fetuses with prenatally detected polyhydramnios were delivered spontaneously, and 4 were delivered via CS. Thus, the prenatal detection of polyhydramnios did not automatically necessitate a Cesarean delivery, as reported previously [13].

Data on the postnatal adaptions of newborns with EA \pm TEF are rare. We observed a range of function from increasing Apgar scores within the first ten minutes of life to normal vitality in the vast majority of children. The median Apgar scores after 5 and 10 minutes were 9 and 10, respectively. Only one infant required resuscitation after a Caesarian section delivery for fetal distress (UApH 7.14, Gross type D, subglottic stenosis, trisomy 21).

The median BW of $2660 \mathrm{~g}$ at a median GA of 38 weeks indicates intrauterine growth retardation among our study sample. The association of small for gestational age with major birth defects has been studied recently in a large population-based sample [14]. Approximately one-third of neonates with EA \pm TEF had BWs below the $5^{\text {th }}$ centile [2]

The presented series encompasses the major types of EA. It must be noted that patients with isolated EA are underrepresented in our study [4]. 


\subsection{Accompanying Malformations}

Consistent with the literature, $60 \%$ of our patients had accompanying malformations [1] [12] [15] [16]. The presence of major congenital malformations of the heart has important prognostic value; between $23 \%$ and $30 \%$ of EA cases have such malformations. In our series, all of the infs. were evaluated preoperatively with echocardiography, and $17 \%$ had a MCM defined as the presence of a hemodynamically relevant abnormality of the heart. No patient in this group required urgent cardiac surgery during the primary hospital stay. However, the infant with a mild form of coarctation of the aorta died as a result of pulmonary hypertension.

Coincident gastrointestinal malformations are of special importance in infs. with EA \pm TEF.

In both of our cases with congenital duodenal obstruction diagnosis was established during the postoperative period and repair was performed in a second operation without further problems.

\subsection{Timing of Operation and Length of Stay (LOS)}

Infs. with EA \pm TEF carry a high risk of developing respiratory problems [17] [18]. Overflow of saliva, reflux, upper airway instability, and gastric overextension contribute to progressive deterioration. Urgent surgery is recommended [12] [19]. In the European survey, $83.4 \%$ of cases of EA \pm TEF were detected at birth, and $15.4 \%$ were detected in the first week of life [1]. Knottenbelt et al. [20] recommend surgery on the first or second day.

Four-fifths $(83 \%)$ of our patients underwent a primary repair within 2 days after delivery. Three patients with TEF and one patient with type $\mathrm{C}$ atresia did not have surgery until day 9. The only exception was an infant who had trisomy 13 , isolated TEF, and a cardiac septal defect, for whom surgery was postponed until day 55. In a comparable study, $68 \%$ of infs. had surgery on day 2 [21]. In a Canadian report, $78 \%$ of infs. had undergone surgery by 4 days of age [22].

During surgery, we always insert a transanastomotic feeding tube for postoperative gastric decompression and early enteral feeding. Gastrostomies were only performed when required. Research has shown that gastrostomy insertion does not protect the anastomosis, and furthermore, it increases the rate of gastroesophageal reflux [16]. In a single-institution series, the gastrostomy rate was reduced from $90 \%$ in the 1980 s and 1990 s to $28 \%$ in the last 10 years of the observation period [11]. The European survey revealed that only $2 \%$ of responders routinely create a gastrostomy at the time of EA \pm TEF repair [4].

The LOS on the NICU was variable, with a median value of 17.5 days $(27 \pm 9.2)$. This length of stay is longer than the median ICU stay of 12 days and the total average length of initial hospitalization of 28 days ( 8 to 170) reported in a recent study [22]. The North American study reported a median total postoperative length of stay of 23 days [7]. A median length of ICU stay of 13 days (3 to 197) was reported in a single-institution series [21]. 


\subsection{Postoperative Course}

There is no consensus regarding postoperative extubation or continued mechanical ventilation. The extubation of otherwise healthy neonates under epidural anesthesia has been recommended [20]. In a state-of-the-art research study, postoperative elective paralysis and mechanical ventilation for 5 days was recommended for cases with esophageal anastomosis under tension [12]. In the latest European survey, postoperative elective paralysis was the preferred approach of $56 \%$ of responders (range 1 to 7 days) to support healing of the anastomosis and to address concerns about respiratory problems [4]. In contrast, the multi-institutional analysis of Sulkowski et al. [7] reported the use of mechanical ventilation in $93 \%$ of infs.

In the present series, all of the patients were ventilated postoperatively (100\%). As expected, the duration of mechanical ventilation for infs. with isolated TEF was shorter than the ventilation time for infs. with EA + TEF. A regression analysis revealed a nonsignificant inverse correlation between $\mathrm{BW}$ and GA and the duration of ventilation. However, this analysis revealed a statistically reduced postoperative ventilation time for patients who had surgery on the second day after birth. Despite the fact that the majority of patients had surgery on the day of admission, surgery was postponed for 1 day for 11 patients with EA + TEF without negative consequences. Time for adaptation after delivery and transportation may contribute to a good postoperative course. Only unstable and/or very immature infs. with respiratory distress require immediate surgery [12] [16].

Generally, $69 \%$ of the responders to the European survey left a chest drain in situ during the primary repair [4]. In our series, we inserted intrapleural drains in 16 infs. (55\%), mainly to treat pneumothorax in the pre-, intra- and postoperative periods. Only one of these infs. suffered from a chylopneumothorax . Our rate of pneumothorax is lower than the significant rate of pleural effusions reported in other study [11].

\subsection{Mortality, Case Load, and Risk Stratification}

The mortality rates after the initial procedure for EA \pm TEF were $5.4 \%$ in a large multicenter study [7] and 8.6\% after one year in another study [5]. A recently published large study showed that hospital volume has no effect on mortality [7]. In that study, approximately one-fourth of freestanding children's hospitals treated fewer than 5 cases per year [7]. In another recently published study from the United Kingdom and Ireland, 151 newborns with EA \pm TEF from 28 pediatric surgery units were analyzed over a time span of 1 year (average 5.4/year/institution) [5]. Thirty-one percent of the respondents to the recent European survey reported seeing 2 to 5 cases per year, and 3\% reported seeing fewer than 2 cases per year [4]. Thus, with a median frequency of 3.5 cases per year, our unit lies within the limit of other medium-sized tertiary centers.

Our findings demonstrated that infs. with EA \pm TEF have a high rate of acute comorbidities in their first weeks of life, and considerable potential for chronic morbidity must be taken into account [6] [11] [22]. The Spitz risk classification system might predict the outcome of infs. with EA with major cardiac malformations and $\mathrm{BW}<1500 \mathrm{~g}$. 
As reported, the survival of group 1 was $97 \%-98 \%$; for group 3, the survival was $50 \%$ [16]. Regarding our patients, $63 \%$ were considered to be in group 1, 30\% were in group 2 , and $7 \%$ were in group 3 . Our series included 5 patients with significant cardiac malformations according to the Leonard et al. [23] and one patient with coarctation of the aorta. Two of our patients died; however, the only patient who died following surgical repair was classified as group 2 (coarctation of the aorta).

Spitz's risk classification does not include the influence of chromosomal trisomy on survival. For instance, infs. with EA \pm TEF and Edwards syndrome (trisomy 18) have a markedly reduced 1-week survival of approximately 10\% [1]. For these infs., avoiding surgery and providing palliative treatment instead might be justified; such an approach has been reported in the literature [3] [6].

In addition to the patients' demographic characteristics and comorbidities, the hospital-level resources (neonatologists, anesthesiologists, and trained nurses) are of utmost importance for a good quality of care. In addition, the experience and skill of the pediatric surgeon are important variables for the procedure's quality and outcome [24]. Near-complete surgical subspecialization in EA \pm TEF, as reported at Alder Hey Children's Hospital (United Kingdom), might increase case load and can improve outcomes. Furthermore, such specialization facilitates training in pediatric surgery [25].

\section{Conclusion}

In conclusion, patients with $\mathrm{EA} \pm \mathrm{TEF}$ showed mild intrauterine growth retardation. Affected infs. carry a high rate of comorbidities. Our results support the hypothesis that surgical repair can be postponed until the first postnatal days without negative consequences in most cases.

\section{Acknowledgements}

The author is grateful to the parents and neonatologists who place their confidence in him and the team of the Department of Pediatric Surgery in Herne/Bochum. He thanks all of the pediatric surgeons, neonatal intensivists and anesthesiologists, and nurses who have been involved with these children since their first days of life.

\section{References}

[1] Pedersen, R.N., Calzolari, E., Husby, S., et al. (2012) Oesophageal Atresia: Prevalence, Prenatal Diagnosis and Associated Anomalies in 23 European Regions. Archives of Disease in Childhood, 97, 227-232. http://dx.doi.org/10.1136/archdischild-2011-300597

[2] Goyal, A., Jones, M.O., Couriel, J.M., et al. (2006) Oseophageal Atresia and Tracheoesophageal Fistula. Archives of Disease in Childhood-Fetal and Neonatal Edition, 91, F381-F384. http://dx.doi.org/10.1136/adc.2005.086157

[3] Kirby, C., Hutson, J., Bennetts, J., et al. (2014) Surgery for Esophageal Atresia. In: Coventry, B.J., Ed., Pediatric Surgery. Complications, Risks and Consequences, Springer, London, Heidelberg, New York, Dordrecht.

[4] Zani, A., Eaton, S., Hoellwarth, M.E., et al. (2014) International Survey on the Management of Esophageal Atresia. European Journal of Pediatric Surgery, 24, 3-8. 
http://dx.doi.org/10.1055/s-0033-1350058

[5] Allin, B., Knight, M., Johnson, P., et al. (2014) Outcomes at One Year Post Anastomosis from a National Cohort of Infants with Oesophageal Atresia. PLOS ONE, 9, e106149. http://dx.doi.org/10.1371/journal.pone.0106149

[6] Kouji, N., Genshirou, E., Risda, T., et al. (2013) Current Profile and Outcome of 100 Esophageal Atresia Patients in the Kyushu Area of Japan. Open Journal of Pediatrics, 3, 239242. http://dx.doi.org/10.4236/ojped.2013.33042

[7] Sulkowski, J.P., Cooper, J.N., Lopez, J.J., et al. (2014) Mobidity and Mortality in Patients with Esophageal Atresia. Surgery, 156, 483-491. http://dx.doi.org/10.1016/j.surg.2014.03.016

[8] Petrie, A. and Sabin, C. (2009) Medical Statistics at a Glance. Wiley-Blackwell, Oxford.

[9] Bar-Maor, J.A., Shoshany, G. and Sweed, Y. (1989) Wide Gap Esophageal Atresia: A New Method to Elongate the Upper Pouch. Journal of Pediatric Surgery, 24, 882-883. http://dx.doi.org/10.1016/S0022-3468(89)80587-1

[10] Gough, M.H. (1980) Esophageal Atresia-Use of an Anterior Flap in the Difficult Anastomosis. Journal of Pediatric Surgery, 15, 310-311. http://dx.doi.org/10.1016/S0022-3468(80)80143-6

[11] Lacher, M., Froehlich, S., von Schweinitz, D., et al. (2010) Early and Long Term Outcome in Children with Esophageal Atresia Treated over the Last 22 Years. Klinische Pädiatrie, 222, 296-301. http://dx.doi.org/10.1055/s-0030-1249610

[12] Spitz, L. (2007) Oesophageal Atresia. Orphanet Journal of Rare Diseases, 2, 24. http://dx.doi.org/10.1186/1750-1172-2-24

[13] Case, A.P., Colpitts, L.R., Langlois, P.H., et al. (2012) Prenatal Diagnosis and Caesarean Section in a Large Population-Based Birth Defect Registry. Journal of Maternal-Fetal \& Neonatal Medicine, 25, 395-402. http://dx.doi.org/10.3109/14767058.2011.580801

[14] Miquel-Verges, F., Mosley, B.S., Blocks, A.S., et al. (2014) A Spectrum Project: Preterm Birth and Small-for-Gestational Age among Infants with Birth. Journal of Perinatology, 35, 198-203. http://dx.doi.org/10.1038/jp.2014.180

[15] Rokitansky, A., Kolankaya, A., Bichler, B., et al. (1994) Analysis of 309 Cases of Esophageal Atresia for Associated Congenital Malformations. American Journal of Perinatology, 11, 123-128. http://dx.doi.org/10.1055/s-2007-994571

[16] Spitz, L. (2006) Esophageal Atresia. Lessons I Have Learned in a 40-Year Experience. Journal of Pediatric Surgery, 41, 1635-1640. http://dx.doi.org/10.1016/j.jpedsurg.2006.07.004

[17] Cozzi, D.A., Capocaccia, P., Roggini, M., Matrunola, M., Morini, F. and Cozzi, F. (2001) Respiratory Status of Infants with Esophageal Atresia. Pediatric Surgery International, 17, 92-96. http://dx.doi.org/10.1007/s003830000465

[18] Grosfeld, J.L. and Ballantine, V.N. (1978) Esophageal Atresia and Tracheoesophageal Fistula: Effect of Delayed Thoracotomy on Survival. Surgery, 84, 394-401.

[19] Pinheiro, P.F.M., Simoes e Silva, A.C. and Pereira, R.M. (2012) Current Knowledge on Esophageal Atresia. World Journal of Gastroenterology, 18, 3662-3672. http://dx.doi.org/10.3748/wjg.v18.i28.3662

[20] Knottenbelt, G., Skinner, A. and Seefelder, C. (2010) Tracheo-Oesophageal Fistula (TOF) and Oesophageal Atresia (OA). Best Practice \& Research Clinical Anaesthesiology, 24, 387401. http://dx.doi.org/10.1016/j.bpa.2010.02.010

[21] Ojha, S., Elvidge, L., Davies, B. and Deorukhkar, A. (2011) Experience of Managing Oesophageal Atresia \pm Tracheoesophageal Fistula in a Tertiary Surgical Neonatal Centre in the UK. Archives of Disease in Childhood. Fetal and Neonatal Edition, 96, Fa23-Fa24. 
http://dx.doi.org/10.1136/archdischild.2011.300164.25

[22] Bjornson, C.L. and Mitchell, I. (2006) Congenital Tracheoesophageal Fistula and Coordination of Care: Expectations and Realities. Paediatrics and Child Health, 11, 395-399.

[23] Leonard, H., Barrett, A.M., Scott, J.E.S. and Wren, C (2001) The Influence of Congenital Heart Disease on Survival of Infants with Oesophageal Atresia. Archives of Disease in Childhood. Fetal and Neonatal Edition, 85, F204-F206. http://dx.doi.org/10.1136/fn.85.3.F204

[24] McAteer, J.P., LaRiviere, C.A., Drugas, G.T., et al. (2013) Influence of Surgeon Experience, Hospital Volume, and Speciality Designation on Outcomes in Pediatric Surgery: A Systematic Review. JAMA Pediatrics, 167, 468-475. http://dx.doi.org/10.1001/jamapediatrics.2013.25

[25] Jawaid, W., Chan, B. and Jesudason, E.C. (2012) Subspecialization May Improve an Esophageal Atresia Service but Has Not Addressed Declining Trainee Experience. Journal of Pediatric Surgery, 47, 1363-1368. http://dx.doi.org/10.1016/j.jpedsurg.2011.12.003

\section{Submit or recommend next manuscript to SCIRP and we will provide best service} for you:

Accepting pre-submission inquiries through Email, Facebook, LinkedIn, Twitter, etc. A wide selection of journals (inclusive of 9 subjects, more than 200 journals)

Providing 24-hour high-quality service

User-friendly online submission system

Fair and swift peer-review system

Efficient typesetting and proofreading procedure

Display of the result of downloads and visits, as well as the number of cited articles Maximum dissemination of your research work

Submit your manuscript at: http://papersubmission.scirp.org/ 